\title{
FILIAL PIETY: STUDI PENGARUH KOMITMEN RELIGIOUS, GRATITUDE, DAN DEMOGRAFI TERHADAP FILIAL PIETY
}

\author{
Rika Rostika Johara \\ UIN Syarif Hidayatullah Jakarta \\ rika_ros@yahoo.com
}

\author{
Ikhwan Lutfi \\ Ikatan Psikologi Sosial \\ Ikhwan.lutfi@uinjkt.ac.id
}

\begin{abstract}
This study aims to determine the effect of the religious commitment, and gratitude on the youth filial piety in Indonesia, particularly in the Ciputat village. The author also adds demographic variables of age and sex to determine their effects on youth filial piety. The sample in this study were 239 youths in the village of Ciputat. The sampling technique used in this research is nonprobability sampling and analysis of the data in this study using multiple regression test. The results indicate that the gratitude and religious commitment affects filial piety. Independent variables are tested using multiple regression, there are five significant independent variable (religious values, religious belief, appreciation for other, age, and gender). These results indicate the proportion of the variance of youth filial piety which explained all the independent variables is $39.2 \%$ and $60.8 \%$ were influenced by other variables outside the research.
\end{abstract}

Keywords: Filial Piety, Religious Commitment, Gratitude

\begin{abstract}
Abstrak
Penelitian ini bertujuan untuk mengetahui pengaruh komitmen religius, dan rasa syukur terhadap kesalehan pemuda di Indonesia, terutama daerah Ciputat. Peneliti juga menambahkan variabel demografik, umur dan jenis kelamin untuk mengetahui pengaruh mereka pada kesalehan pemuda. Sampel pada penelitian ini merupakan 239 anak muda di daerah Ciputat. Teknik sampling yang digunakan pada penelitian ini adalah nonprobablity sampling dan analisis data pada penelitian ini menggunakan uji multiple regression. Hasil dari penelitian ini mengindikasikan bahwa rasa syukur dan komitmen religius mempengaruhi kesalehan. Variabel bebas piuji menggunakan multiple regression, ada lima variabel bebas yang signifikan (nilai religius, keyakinan religius, apresiasi terhadap orang lain, umur, dan jenis kelamin). Hasil ini mengindikasikan proporsi dari varians kesalehan pemuda yang dijelaskan oleh semua variabel bebas sebesar 39.2\% dan 60.8\% lainnya dipengaruhi oleh variabel diluar penelitian.
\end{abstract}

Kata Kunci: Kesalehan Pemuda, Komitmen Religius, Rasa Syukur 


\section{PENDAHULUAN}

Hubungan kekerabatan masyarakat Indonesia begitu kuat, sehingga kultur/ budaya keluarga besar masih tetap ada dalam masyarakat Indonesia (Koentjoroningrat, 1991). Yaitu keluarga yang memiliki struktur orang tua, anak dan cucu. Relasi anak dan orang tua, termasuk kakek-nenek masih mendasarkan pada etika dan ajaran keagamaan, dimana berbakti kepada orang tua memegang peranan yang penting dalam relasi tersebut. Seorang anak memiliki kewajiban untuk berbakti dan menghormati orang tuanya. Pola relasi ini dalam psikologi disebut sebagai filial piety.

Konstruk filial piety menurut Ho (1994) memiliki arti sebagai kondisi positif dimana seorang anak berbuat baik kepada orang tuanya, yang meliputi pemenuhan kebutuhan orang tua secara prilaku dan emosi, dalam bentuk perilaku yang meliputi pembayaran/pembiayaan, tanggung jawab, dan pengorbanan; dan emosi, yang meliputi cinta / kasih sayang, harmoni, dan rasa hormat. Dengan kata lain, filial piety terekspresikan dalam bentuk peduli, menunjukkan rasa hormat, ucapan, menyenangkan, mematuhi, dan memberikan dukungan keuangan, yang dilakukan anak terhadap orang tuanya.

Filial piety dalam masyarakat Indonesia menempati posisi yang sangat penting. Salah satu landasannya adalah posisi orang tua yang sangat tinggi dalam struktur kemasyarakatan. Tradisi dan budaya semua suku bangsa di Indonesia, sangat menghormati dan memberi tempat yang tinggi bagi kedua orang tua, terutama bagi ibu (Koentjoroningrat, 1991). Filial piety merupakan etika sosial yang selalu ditekankan, di mana anak diminta untuk selalu menurut pada orang tua. Secara sosial, berbakti kepada orang tua merupakan bagian dari ukuran kesalehan anak. Ketidaktaatan anak terhadap orang merupakan hal yang sangat buruk dan akan sangat rendah derajatnya. Aturan kemasyarakatan tentang perlakuan terhadap orang tua tergambarkan dari cerita rakyat yang tumbuh dan berkembang di masyarakat. Salah satu contohnya adalah cerita Malin Kundang.

Selain berdasarkan pada ajaran dan aturan etika kemasyarakatan, semua agama memiliki kesamaan dalam perlakuan anak terhadap orang tua. Istilah yang digunakan adalah Birr al walidain (berbuat baik kepada kedua orang tua) atau bakti pada orang tua. Dalam Islam, anak memiliki kewajiban untuk berbakti dan patuh pada orang tua mereka. Bahkan perintah untuk berbakti kepada orang tua adalah perintah kedua setelah keimanan. Setelah memerintahkan untuk hanya menyembah kepada-Nya 
dan tidak mempersekutukannya, perintah selanjutnya adalah berbuat baik kepada kedua orangtua.

Dalam al quran ada dua puluh kali kata walidain (kedua orang tua) dengan berbagai bentuk, ditemukan aneka ragam perintah Allah mengenai filial piety, antara lain seperti berbuat ihsan (kebaktian) dan husn (kebaikan), berwasiat untuk orang tua menyangkut warisan (sebelum turun ayat-ayat yang mengatur pembagian warisan), memberi nafkah, mensyukuri, dan memohonkan untuk mereka ampun dan rahmat, serta pengajaran Allah kepada anak agar bermohon kepada Allah agar kiranya diilhami kemampuan dan kepandaian mensyukuri nikmat-Nya terhadap mereka (anak-anaknya) dan orang tua, yakni karena dengan nikmatnya itulah orang tua dapat melindungi dan memelihara anak-anaknya (Shihab, 2014).

Tuntutan agar anak menjadi berbakti pada orang tua, tidak hanya dipengaruhi oleh ajaran agama dan etika sosial, tetapi juga ada peran dan harapan dari orang tua. Sebagaimana pendapat Qurays Shihab (2014) yang menyatakan bahwa filial piety dibangkitkan dalam rangka agar anak dapat menjadi orang berbakti seperti yang dicita-citakan oleh orang tua (Shihab, 2014). Sarwono (2006) menambahkan bahwa factor lain yang mendukung munculnya tuntutan dari orang agar anaknya berbakti adalah rasa ketergantungan pada orang tua terhadap anaknya demikian besar. Hasil penelitian psikolog Turki, C. Kagitcibasi (dalam Sarwono, 2006), menyebutkan bahwa ibu-ibu dari suku Jawa dan Sunda mengharapkan anak mereka agar menuruti orang tua (Jawa: $88 \%$, Sunda: $81 \%$ ), demikian pula ayah dari kedua suku tersebut (Jawa: $85 \%$, Sunda: $76 \%$ ).

Walaupun memiliki peran dan posisi sangat penting dalam kehidupan keagamaan dan kemasyarakatan di Indonesia, tetapi kenyataan di lapangan belum sepenuhnya terwujud. Filial piety masyarakat Indonesia mendapatkan sorotan tajam. Hal ini disebabkan oleh munculnya kasus-kasus yang mengindikasikan adanya ketidakpatuhan/ketidakberbaktian anak terhadap orang tuanya. Banyak ditemukan konflik orang tua dan anak. Beberapa kasus yang mendapat liputan dari media massa diantaranya adalah Marshanda yang menggugat orang tuanya ke pengadilan, Princess Santang di Bogor yang mengusir ibu dan saudaranya serta menggugatnya ke pengadilan tahun 2013 (www.kabarkabari.com), nenek Fatimah yang digugat oleh anak dan menantunya (www.liputatenam.com), gugatan Ani Hadi terhadap ayah dan ibu kandungnya Tjokrohadi dan istrinya oleh anaknya, Ani Hadi, dengan tuduhan melakukan wanprestasi terhadap hibah harta warisan pada tahun 2014 (www.liputanenam.com). Di kota 
Makassar, Rendra Rizkiyansyah menggugat bapakya yang bernama Rusman Rahman sebesar Rp 1,5 milyar karena merasa ditelantarkan selama 23 tahun lamanya (www.detik.com).

Fenomena lainnya adalah munculnya kecenderungan untuk menitipkan orang tua yang sudah lanjut usia ke panti jompo. Seperti kasus oma Maria, yang mengaku ia lebih terperhatikan tinggal di panti karena di

rumah atmosfer kasih sayang baginya sudah terpolusi (www.indomedia.com). Kasus lainnya adalah seorang anak tunggal yang menitipkan ibunya ke panti jompo, karena sang ibu selalu bermasalah dengan suaminya (Suara pembaruan,26/10/03). Lain lagi dengan keluarga di Surabaya, seorang anak menitipkan bapaknya ke panti jompo dengan alasan kesibukan (www.pikiranrakyat.com). Sedangkan di Bandung juga disebutkan seorang anak dan menantu mengirim ayahnya untuk tinggal di panti werdha dengan alasan supaya punya teman untuk berkumpul (www.tiberias.or.id). Peristiwa lain terjadi di Panti werdha Wisma Mulia, Jelambar, Jakarta Barat bahwa orang tua lanjut usia yang dititipkan anaknya di sana, karena kuatir tidak ada yang dapat mengawasi (www.pikiran-rakyat.com).

Yeh dan Bedford (2004) melaporkan bahwa konflik orang tua dan anak remaja (responden penelitian siswa SMP dan SMA) berkorelasi secara signifikan dengan tipe filial piety, yaitu nonfilial, authoritarian, reciprocal, dan absolute. Yeh dan Bedford menguji hubungan filial piety dengan frekuensi, sumber, dan solusi konflik orang tua dengan anak. Dalam penelitian tersebut diidentifikasi enam bentuk sumber konflik, yaitu konflik permintaan orang tua versus keinginan anak, keinginan anak tidak sesuai dengan kemampuan orang tua, konflik peran, perilaku orang tua tidak rasional, permintaan orang tua tidak bermoral, dan perselisihan antar orang tua. Pada masing-masing tipe filial piety, konflik permintaan orang tua versus keinginan anak menjadi konflik yang paling sering terjadi

Komitmen religius (religious commitment) erat kaitanya dengan filial piety. Reese (2003), menyatakan bahwa filial piety menyatu dalam agama besar di Cina (Chinese religion). Davidson dan Knudsen (1977) mendefinisikan religious commitment sebagai interaksi antara kesadaran beragama masyarakat dan partisipasi keagamaan. Di mana religious commitment dapat mempengaruhi prilaku dan tindakan individu (Worthington dalam Kidwell, 2009). Konsep filial piety berkaitan erat dengan budaya dan agama/ajaran. Dalam penelitian Dessi (2010) mengenai Social behavior and religious consciousness among Shin Buddhist 
practitioners, filial piety menyumbang $85,0 \%$ terhadap nilai-nilai tradisi ajaran Shin Buddhist. Begitu pula dengan ajaran agama Islam, Islam mewajibkan dan memaksa para pemeluknya untuk memiliki komitmen dalam beragama Islam, meskipun Islam tidak pernah memaksa seseorang untuk memeluk ajaran Islam. Sehingga seluruh ajaran dan aturannya wajib untuk dilaksanakan termasuk filial piety yang termuat dalam aturan syariah mengenai ahlak al banin. (Jainuri, 2012).

Selain itu filial piety juga erat kaitannya dengan rasa syukur (gratitude). Sebuah penelitian menunjukan bahwa filial piety adalah ekspresi dari gratitude, sebagai rasa terimakasih atas usaha orang tua yang telah merawat seorang anak (Yeh dalam Yeh \& Bedford, 2003). Luk-Fong (2005) dalam penelitiannya mengutip salah satu contoh responden yang diwawancarai mengenai bentukbentuk tradisional dan modern filial piety:

"Ini jauh lebih baik bahwa anak menghormati orang tua dan menunjukkan filial piety dari rasa syukur (gratitude) dan bukan karena kewajiban (obligation)."

Kata gratitude maknanya berkisar antara lain pada pujian atas kebaikan, serta penuhnya sesuatu. Gratitude digunakan juga untuk menunjuk balasan yang banyak dari pemberian yang (Shihab, 2014).

Gender atau jenis kelamin juga menjadi salah satu variabel yang memiliki pengaruh besar terhadap filial piety, meski pun berbasis budaya. Seperti yang dilaporkan dalam penelitian Yue dan $\mathrm{Ng}$ (1999) yang mencatat perbedaan gender dalam praktek filial piety di kalangan anak muda di Beijing. Bentuk filial piety bagi anak laki-laki membantu orang tua secara finansial, sedangkan bagi anak perempuan adalah kepedulian untuk dalam menjaga hubungan dengan orang tua. Yi dan Lin (2009) menemukan pola yang sama di Taiwan, di mana anak laki-laki yang sudah menikah lebih mendukung filial piety dibandingkan anak perempuan yang sudah menikah, sedangkan anak perempuan yang sudah menikah ingin menjaga kontak sesering mungkin, memberikan dukungan emosional, dan terlibat dalam pertukaran seperti bantuan timbal balik dalam pekerjaan rumah tangga. Studi yang dilakukan di Hong Kong oleh Chan dan Lee (1995) dan Ngan dan Wong (1995) mengungkapkan bahwa anak laki-laki membuat sebagian besar keputusan keluarga dan memberikan dukungan keuangan kepada orang tua, sedangkan anak perempuan mengambil tugas-tugas yang menunjukkan perilaku peduli. 


\section{Filial Piety}

Filial piety berasal dari bahasa Latin, filiālis dan pietas. Filial merujuk pada kata filius (anak laki-laki)/filia (anak perempuan),yang berarti menjadi keturunan (generasi) yang diperoleh sebagai hasil dari perkawinan parental (ensiklopedia bebas, www.wikipedia.com). Kata piety berasal dari kata pietas, yang berarti taat, atau pengabdian, (ensiklopedia bebas, www.wikipedia.com). Sehingga filial piety secara bahasa diartikan menjadi menghormati pengorbanan orang tua dan leluhur.

Ho (1994) menyatakan bahwa filial piety adalah hubungan antar generasi. Yeh dan Bedford (2003) mengatakan, filial piety merupakan pusat konsep dalam Konfusionisme mengandung ide-ide penting tentang bagaimana anak-anak harus merawat orang tua mereka. Bakti (filial piety) menuntut sesuatu yang bersifat materi dan emosional, seperti support (dukungan), memorializing (mengingat-ingat), attendance (kehadiran), deference (keseganan), compliance (kepatuhan), respect (rasa hormat), dan love (kasih sayang/cinta), dan stuktur tersebut sering kali digeneralisasikan berlaku untuk hubungan di luar keluarga (Yeh \& Bedford, 2003).

Ho (1994) menjelaskan, filial piety adalah contoh budaya yang didefinisikan sebagai hubungan intergenerasi. Meskipun beberapa komponen filial piety (seperti kepatuhan) dipengaruhi oleh budaya, tetapi filial piety merupakan dasar kemanusiaan.

Filial piety adalah kebajikan tertinggi yang menekankan pada usaha anak dan cucu laki-laki untuk memelihara nama baik keluarga (Wawrytko dalam Hsu, Hui, \& Waters, 2001). Tho dan Binh (2012), mendefinisikan filial piety sebagai berikut:

"Filial piety means to be good to one's parents: to engage in good conduct not just towards parents but also outside the home so as to bring a good name to one's parents and ancestors; to perform the duties of one's job well so as to obtain the material means to support parents as well as carry out sacrifices to the ancestors; not be rebellious; show love, respect, and support; display courtesy: ensure male heirs, uphold fraternity among brother; wisely advise one's parents, including sorrow for their sickness and death. But a core ideal of filial piety is the fulfillment of child's obligation to the parents."

Tho dan Binh (2012) juga menyatakan bahwa filial piety adalah sentimen positif, yaitu keharusan anak menunjukan penghormatan dan ketaatan kepada orang tua. Bertanggung jawab dengan tugas kakek-nenek 
dan orang tua. Filial piety tidak hanya dilihat sebagai etika yang paling atas, akan tetapi sebagai asal dari kebahagiaan. Berdasarkan nilai kebajikan, filial piety dalam keluarga didefinisikan sebagai hormat, memberi perawatan yang baik bagi keluarga, dan tulus (Tho \& Binh, 2012). Ho (1994) menyatakan filial piety menentukan bagaimana anak harus bertingkah laku sesuai dengan keinginan orang tua mereka, baik orang tua masih hidup atau pun sudah meninggal. Hal tersebut membenarkan secara absolut otoritas orang tua yang lebih kepada anak.

Pendapat serupa dikemukakan oleh Guadagno (dalam Li, 2011), yang menyatakan bahwa filial piety difokuskan pada rasa hormat (respect), penghormatan (reverence), perawatan (care), kepatuhan (obedience), dan mengabulkan perintah (fulfilling duty) untuk orang tua dan kakek-nenek. Li (2011) juga menjelaskan bahwa filial piety ditanamkan tidak hanya dalam lingkup keluarga tetapi juga dalam jaringan antara orang tua dan anak, suami dan istri, tetangga, teman, komunitas dan institusi. Filial piety secara fundamental tentang hubungan, bukan hanya hubungan antara anak dengan orang tuanya, tetapi juga antara orang dengan komunitas atau masyarakat.

Dari semua pemaparan definisi filial piety di atas, penulis menyimpulkan filial piety dalam penelitian ini adalah hubungan baik antara anak dengan orang tua, dalam bentuk perilaku yang meliputi bahasa, tanggung jawab, dan pengorbanan; dan emosional, yang meliputi cinta / kasih sayang, harmoni, dan rasa hormat.

\section{Jenis-Jenis Filial Piety}

Chow (2001) membedakan tiga jenis filial piety dalam tiga bentuk perilaku. Pertama kewajiban anak untuk memenuhi kebutuhan material orang tua. Kedua adalah perilaku anak untuk selalu mendengarkan orang tua dan mematuhi keinginan mereka. Ketiga adalah usaha anak untuk menyenangkan dan menghormati orang tua.

Pendapat yang sedikit berbeda dikemukaan oleh Tho dan Bihn (2012) dalam menggambarkan ekspresi filial piety. Pertama adalah anak harus berterimakasih dan hormat kepada kakek-nenek dan orang tua dalam keluarga. Ketika mereka masih hidup, anak-anak harus memberikan penghormatan, dukungan, dan perhatian kepada mereka. Ketika mereka tua, anak harus memberikan dukungan dan perhatian yang lebih besar. Dan ketika mereka sudah meninggal, anak-anak harus mengubur mereka dengan disertai harta benda di dalamnya. 
Perilaku kedua adalah membuat bangga orang tua atau leluhur. Usaha yang dapat dilakukan untuk menumbuhkan rasa bangga orang tua adalah dengan kemampuan melindungi diri sendiri, bertingkah laku sesuai dengan moral, sehat, memiliki kepribadian yang baik, menjadi manusia yang berbudi luhur dan murah hati, membawa kemasyhuran untuk keluarganya, dan terakhir adalah memiliki karir yang sukses. Perilaku ketiga adalah tidak pernah melakukan sesuatu yang dapat menimbulkan pengaruh negatif terhadap keluarganya. Mampu untuk meningkatkan karir keluarganya, melanjutkan apa yang mereka inginkan, mengikuti contoh-contoh yang baik, melindungi perintah, tradisi dan jalan hidup keluarga.

Yeh (dalam Yeh \& Bedford, 2003) membagi filial piety menjadi dua bentuk, yaitu reciprocal filial piety dan authoritarianism filial piety. Reciprocal filial piety meliputi kehadiran secara emosional dan spiritual untuk orang tua mereka sebagai rasa syukur atas usaha mereka, dan merawat orang tua secara fisik dan finansial ketika mereka (orang tua) bertambah usia dan meninggal dunia. Authoritarianism filial piety bersifat otoriterisme, dogmatisme, dan menuntut kesesuaian. Authoritarianism filial piety memerlukan penekanan keinginan diri sendiri yang sesuai dengan keinginan orang tua karena senioritas mereka dalam hal fisik, keuangan ataupun sosial. Serta menjaga garis keturunan keluarga, menjaga reputasi orang tua. Authoritarianism filial piety menonjolkan hirarki dan penyerahan.

\section{Religious Commitment}

Davidson dan Knudsen (1977) mendefinisikan komitmen religius sebagai interaksi antara kesadaran beragama masyarakat dan partisipasi keagamaan. Sedangakan Metthews, McCullogs, Larson, Koenig, Swyers, dan Milano (1998) mendefinisikan komitmen religious sebagai partisipasi atau dukungan praktek, keyakinan, sikap, atau sentimen yang berhubungan dengan komunitas iman terorganisir. Menurut Takamizawa (1999) komitmen religius sebagai sebuah komitmen dalam menyelamatkan dirinya sendiri atau orang lain demi menjaga keseimbangan sosial dan ritual.

Koenig, McCullogh, dan Larson (2001) mengatakan bahwa komitmen religious menunjukan seberapa besar seseorang terlibat dalam agamanya. Dilain pihak, Worthington, McCullogh, Ripley, Berry, O`Connor, Bursley, dan Schmitt (2003) mendefinisikan komitmen religious sebagai derajat dimana seseorang taat terhadap religious value, religious beliefs, dan religious practices, dan menggunakannya dalam kehidupan sehari-hari. 
Menurut Worthington (dalam Chong, 2009) religious commitemnt menunjukan jumlah waktu yang dihabiskan dalam keterlibatan agama pribadi, afiliasi keagamaan, kegiatan berorganisasi keagamaan, dan kepentingan keyakinan agama, yang dipraktekan dalam kehidupan sehari-hari secara intrapersonal dan interpersonal. Dengan kata lain, dimensi yang ditawarkan oleh Worthington dkk adalah Religious values merupakan religiusitas instrinsik yang melibatkan penilaian dan pemaknaan seseorang tehadap agama yang dianutnya. Religious beliefs adalah Religius instrinsik yang melibatkan pernyataan bahwa seseorang memegang teguh terhadap spiritualitas agama yang dianutnya. Religious practices adalah religius ekstrinsik yang melibatkan intensitas prilaku seseorang dalam kegiatan keagamaan.

Glock (dalam Kidwell, 2009) mendefinisikan komitmen religius sebagai keterlibatan seseorang dalam hal-hal berikut ini, (a.) experential commitment, reaksi emosional individu ketika berkomunikasi dengan Tuhan, atau dengan kekuatan transeden agama tertentu. (b.) Ideological commitment, terjadi ketika individu mendukung dan menjalankan sistem kepercayaan yang digariskan oleh keyakinan agamanya. (c.) Ritualistic commitment, individu mengikuti praktek tradisi keagamaan mereka. Pada intinya, prilaku mereka, seperti kehadiran dilayanan keagamaan partisipasi dalam sekramen agama adalah tanda dari komitmen mereka. (d.) Intelectual commitment, memperoleh pengetahuan dengan rinci tentang tradisi iman mereka, misalnya pengetahuan tentang teksteks suci dan pendiri agama atau pemimpin.(e.). Consequential commitment, meliputi efek sekuler dari keyakinan beragama, praktek beragama, pengalaman, dan pengetahuan agama pada masing-masing individu.

\section{Gratitude}

Kata gratitude (syukur) berasal dari bahasa Latin, gratia, yang berarti anugrah, kemurahan hati, atau bersyukur. Seluruh turunan dari bahasa Latin ini mengakar pada —harus dilakukan dengan kebaikan, kemurahan hati, memberi, keindahan memberi dan menerima, atau memperoleh sesuatu bukan untuk tujuan apapun. \| Gratitude dikonsepkan sebagai emosi, sikap, kebaikan moral, kebiasaan, trait kepribadian, dan respon coping (Pruyser dalam Emmons, McCullough \& Tsang, 2004). McCullough, Kilpatrick, Emmons, dan Larson (dalam Wangwan, 2014) berpendapat bahwa rasa syukur adalah emosi moral yang yang merespon baik perilaku moral dan motivator perilaku moral. Definisi umum gratitude adalah 
perasaan yang dialami ketika beneficiary (seseorang yang mendapat bantuan) menerima keuntungan dari benefactor (seseorang yang memberi bantuan) (Lambert \& Fincham, 2011).

Wangwan (2014) mengatakan syukur adalah respon emosional ketika orang melihat kebajikan dari orang lain yang memberikan bantuan. Roberts (Wangwan, 2014) mendefinisikan gratitude sebagai penerimaan senang kepada orang yang telah bertindak untuk kepentingan kita. Menurut pandangan Roberts, syukur adalah perasaan yang kuat penghargaan terhadap dermawan dan kemauan untuk tetap hutang ke seorang dermawan. Dalam hal ini, terima kasih dapat terdiri dari dua kategori perasaan, perasaan penghargaan kepada dermawan dan perasaan kewajiban untuk balas budi. Ortony, Clore, dan Collins (Wangwan, 2014) mengemukakan bahwa syukur adalah emosi senyawa yang timbul dari kekaguman tindakan terpuji dan pengalaman sukacita ketika perbuatan itu diinginkan untuk diri sendiri.

Menurut studi McCullough et.al. (Wangwan, 2014) pada investigasi hubungan antara rasa syukur dan motivasi prososial, penilaian memerlukan tiga proses psikologis sebagai berikut: a) kognisi-persepsi atau penafsiran terhadap situasi membantu yang dapat mempengaruhi perasaan syukur. b) emosi-emosi bersyukur ditimbulkan dari membantu. c) motivasi-motivasi prososial muncul dari perasaan bersyukur.

Dalam penelitiannya McCullough et.al. (2002), menyatakan perbedaan orang-orang yang kurang bersyukur dan orang-orang yang bersyukur. Orang bersyukur memiliki emosi yang positif dan kepuasan hidup yang lebih tinggi, serta emosi negatif, seperti depresi, kecemasan, dan kecemburuan, yang lebih rendah. Orang-orang tersebut juga secara prososial menjadi lebih berorientasi, bahwa mereka lebih empatik, pemaaf, penolong, dan mendukung, dibandingkan dengan mereka yang kurang bersyukur.sejalan dengan itu, individu yang bersyukur juga kurang fokus pada materialistik. Orang-orang dengan disposisi syukur yang lebih kuat juga cenderung menjadi lebih berpikiran spiritual dan religius.

Penelitian ini mendasarkan batasan gratitude pada kecenderungan untuk mengalami perasaan berterimakasih sebagai apresiasi terhadap kebaikan yang diterima (Watkins, Woodward, Stone, \& Kolts, 2003). Individu yang bersyukur memiliki tiga karakteristik. Pertama, secara positif individu yang bersyukur memiliki perasaan berkecukupan (sense of abundance). Kedua, individu yang bersyukur akan menghargai kontribusi orang lain terhadap kesejahteraan mereka (appreciation of others). Ketiga, 
seseorang yang bersyukur dikarakteristikan dengan kecenderungan menghargai kenikmatan yang sederhana (simple appreciation).

\section{METODE}

Populasi dalam penelitian ini adalah remaja yang berusia 11-20 tahun yang berdomisili di Kelurahan Ciputat, kota Tangerang Selatan. Dengan menggunakan size of random sample Arkin dan Cotton (dalam Lewin, 1979) maka digunakan sampel sebanyak 239 orang, dengan menggunakan teknik pengambilan sampel non-probability sampling, dimana peluang dari setiap remaja di Kelurahan Ciputat memiliki peluang yang sama untuk menjadi sampel penelitian. Teknik pengambilan data menggunakan convenience sampling, dimana kemudahan mendapatkan responden dalam penelitian menjadi pilihan utama.

Variabel dalam penelitian ini adalah filial piety, religious commitment yang meliputi dimensi religious value, religious belief, dan religious practice; gratitude yang meliputi dimensi sense of abundance, appreciation for other, dan simple appreciation; variabel demografi yang meliputi usia dan jenis kelamin. Dependent variable dalam penelitian ini adalah filial piety sedangkan independent variable dalam penelitian ini adalah religious value, religious belief, religious practice, sense of abundance, appreciation for other, simple appreciation, usia dan jenis kelamin.

Pengujian hipotesis yang digunakan dalam penelitian ini adalah regresi berganda. Metode analisis regresi berganda ini digunakan untuk mengetahui besarnya pengaruh lebih dari satu variable bebas (IV) dalam penelitian ini gratitude (sense of abudance, appreciation of other, simple appreciation) dan religious commitment (religious values, religious beliefs, religious practices) terhadap variable terikat (DV) yaitu filial piety. Pada penelitian ini, analisis statistic regresi berganda dihitung dengan menggunakan SPSS versi

19. Sedangkan uji validitas skala menggunakan teknik confirmatory factor analysis (CFA).

\section{Pengukuran}

Filial piety diukur dengan menggunakan skala filial piety (FP scale) yang dikembangkan oleh Ho (1994). Masing-masing item terkait dengan dimensi filial piety, yang berorientasi pada perilaku dan emosional. FP scale terdiri dari 22 item dengan skala 6 poin, 1 untuk sangat tidak setuju dan 6 untuk sangat setuju. Dalam penelitian Ho, skala ini terdiri dari 22 item, 11 item 
favorable, dan 11 item unfavorable. Dikarenakan dimensi jumlah dimensi dalam skala tersebut tidak diketahui, terlebih dahulu peneliti menganalisis skala dengan exploratory factor analysis (EFA), untuk mendapatkan dimensi dan item yang fit dengan data.

Religious commitment diukur dengan menggunakan Religious Commitment Inventory-10 (RCI-10) yang dikembangkan oleh Worthington et.al (2003). Alat ukur ini terdiri dari tiga dimensi yaitu, religious values, religious beliefs, dan religious practices yang memiliki 10 item, 6 item mengukur intrapersonal religious commitment, 4 item mengukur interpersonal religious commitment.

Pengukuran konstruk gratitude berdasarkan pada dimensi Watkins dkk (2003) yang terdiri dari yaitu sense of abundance, appreciation for other, dan simple appreciation sebagaimana yang tercantum dalam alat ukur GRAT (Gratitude, Resentment, and appreciation Test). Perasaan berkecukupan (sense of abundance). Apresiasi sosial (appreciation for other) menunjukkan penghargaan akan kontribusi orang lain dalam kesejahteraan hidupnya. Simple appreciation merujuk pada kecenderungan dalam mengapresiasi kesenangan sederhana. Individu yang mengapresiasi keuntungan subjektif terhadap hal-hal yang sederhana. Ekspresi gratitude menunjukkan pengakuan akan ekspresi rasa syukur.

\section{HASIL}

Gambaran gambaran umum subjek penelitian dapat dilihat pada tabel berikut.

\section{Tabel 1}

Gambaran Umum Subjek Penelitian

\begin{tabular}{|c|c|c|c|c|}
\hline \multirow{2}{*}{ Usia } & \multicolumn{2}{|c|}{ Jenis Kelamin } & \multirow{2}{*}{$\mathbf{F}$} & \multirow{2}{*}{$\%$} \\
\hline & $\mathbf{P}$ & $\mathbf{L}$ & & \\
\hline Remaja Awal (11-14 tahun) & 32 & 33 & 65 & $27,19 \%$ \\
\hline $\begin{array}{l}\text { Remaja Pertengahan (15-17 } \\
\text { tahun) }\end{array}$ & 65 & 77 & 142 & $59,42 \%$ \\
\hline Remaja Akhir (18-20 tahun) & 12 & 20 & 32 & $13,39 \%$ \\
\hline Total & 109 & 130 & 239 & $100,00 \%$ \\
\hline
\end{tabular}

Berdasarkan tabel 1 dapat diketahui bahwa subjek penelitian laki-laki lebih banyak dibandingkan dengan perempuan. Dimana laki-laki berjumlah 130 orang (54,39\%), sedangkan perempuan berjumlah 109 orang $(45,61 \%)$. 
Berdasarkan kelompok usia dapat diketahui bahwa subjek dalam penelitian ini didominasi oleh kelompok usia kategori remaja pertengahan (1517 tahun) yang berjumlah 142 orang $(59,42 \%)$, kemudian disusul oleh kategori usia remaja awal (11-14 tahun) yang berjumlah 65 orang $(27,19 \%)$, dan terakhir kategori usia remaja akhir (18-20 tahun) berjumlah 32 orang (13,39\%).

Hasil penelitian juga menunjukkan kategori skor variable berdasar tinggi dan rendah, sebagaimana terlihat dalam tabel 2

\section{Tabel 2}

Kategorisasi Skor Variabel

\begin{tabular}{lcc}
\hline \multicolumn{1}{c}{ Variabel } & $\begin{array}{c}\text { Rendah } \\
\text { (Percent) }\end{array}$ & $\begin{array}{c}\text { Tinggi } \\
\text { (Percent) }\end{array}$ \\
\hline filial piety & 43,9 & 56,1 \\
Religious Value & 60,3 & 39,7 \\
Religious Belief & 44,8 & 55,2 \\
Religious Practice & 58,2 & 41,8 \\
Sense of Abundance & 50,2 & 49,8 \\
Appreciation for Other & 49,8 & 50,2 \\
Simple Appreciation & 49 & 51 \\
\hline
\end{tabular}

Tabel di atas menujukkan bahwa dari variable psikologi yang diteliti, 4 variabel (filial piety, religious belief, appreciation for other dan simple appreciation) didominsai oleh responden yang memiliki skor tinggi. Yang dimaksud skor tinggi disini adalah skor individu yang berada di atas rata-rata. Dengan kata lain, filial piety, religious belief, appreciation for other dan simple appreciation lebih banyak dibanding responden yang memiliki skor rendah.

Hasil utama dari penelitian ini adalah uji hipotesis penelitian. Yaitu ada pengaruh yang signifikan dari seluruh variable independen terhadap filial piety remaja Tangerang Selatan. Teknik analisis regresi berganda, dengan menggunakan software SPSS 19 menghasilkan diterimanya hipotesis penelitian. Sebagaimana terlihat pada table di bawah ini:

Tabel 3

Tabel Anova

\begin{tabular}{cccccc}
\hline Model & Sum of Squares & Df & Mean Square & F & Sig. \\
\hline Regression & 8428,342 & 8 & 1053,543 & 18,359 &, $000^{\mathrm{a}}$ \\
Residual & 13084,002 & 228 & 57,386 & & \\
Total & 21512,344 & 238 & & & \\
\hline
\end{tabular}


Tabel di atas menunjukkan ada pengaruh yang signifikan dari variabel religious commitment (religious value, religious belief, religious practice), variabel gratitude (sense of abundance, appreciation for other, simple appreciation), dan variabel demografi (jenis kelamin dan usia) terhadap filial piety remaja.

Hal ini berarti pula bahwa perubahan pada independen variable akan diikuti perubahan pada dependen variabel. Selanjutnya adalah kontribusi seluruh IV terhadap DV dapat dilihat pada tabel 4 di bawah ini.

Tabel 4

Tabel R Square

\begin{tabular}{ccccc}
\hline Model & R & R Square & $\begin{array}{c}\text { Adjusted R } \\
\text { Square }\end{array}$ & $\begin{array}{c}\text { Std. Error of the } \\
\text { Estimate }\end{array}$ \\
\hline 1 &, $626^{\text {a }}$ &, 392 &, 370 & 7,57535 \\
\hline
\end{tabular}

Keterangan:

a. Predictors: (Constant), religious value, religious belief, religious practice, sense of abundance, appreciation for other, simple appreciation, usia, jenis kelamin

Dari tabel 4 di atas dapat dilihat bahwa perolehan R square sebesar 0,392 atau $39,2 \%$. Artinya proporsi varians dari filial piety yang dijelaskan oleh semua independent variable (religious value, religious belief, religious practice, sense of abundance, appreciation for other, simple appreciation, jenis kelamin, dan usia) adalah sebesar 39,2\%. Sedangkan $60,8 \%$ sisanya dipengaruhi oleh variabel lain di luar penelitian ini.

Hasil temuan penelitian selanjutnya adalah kontribusi dari setiap variable terhadap perubahan filial piety. Table di bawah ini menggambarkan variable mana sajakah yang memiliki pengaruh yang signifikan terhadap perubahan filial piety.

Tabel 5

Koefisien Regresi

\begin{tabular}{lccccc}
\hline \multirow{2}{*}{\multicolumn{1}{c}{ Model }} & \multicolumn{2}{c}{$\begin{array}{c}\text { Unstandardized } \\
\text { Coefficients }\end{array}$} & $\begin{array}{c}\text { Standardized } \\
\text { Coefficients }\end{array}$ & t & \multirow{2}{*}{ Sig. } \\
\cline { 2 - 5 } & $\mathbf{B}$ & Std. Error & Beta & & \\
\hline (Constant) & 7.579 & 4.441 & & 1.707 & .000 \\
Religious value & .315 & .091 & .242 & 3.455 & .001 \\
Religious belief & .049 & .088 & .037 & .556 & .000 \\
Religious practice & -.001 & .076 & -.001 & -.020 & .984 \\
Sense of abundance & -.035 & .070 & -.034 & -.495 & .621 \\
Appreciation for other & .482 & .082 & .445 & 5.861 & .000 \\
\hline
\end{tabular}




\begin{tabular}{lccccc}
\hline Simple appreciation & .038 & .078 & .037 & .490 & .624 \\
JenisKelamin & -.776 & 1.013 & -.041 & -.766 & .000 \\
Usia & .579 & .826 & .037 & .701 & .014 \\
\hline
\end{tabular}

Berdasarkan koefisien regresi pada tabel 5 dapat diperoleh persamaan regresi sebagai berikut:
Filial Piety $=$ 7,579 +0,315 Religious Value + 0,049 Religious Belief - 0,001 Religious Practice - 0,35 Sense Of Abundance + 0,482 Appreciation For Other + 0,038 Simple Appreciation - 0,776 Jenis Kelamin + 0,579 Usia + e

Berdasarkan data pada tabel di atas, untuk melihat signifikan atau tidaknya koefisien regresi yang dihasilkan, yaitu dengan melihat nilai signifikansi pada kolom yang paling kanan (kolom ke-6). Jika $\mathrm{P}<0,05$, maka koefisien regresi independent variable yang dihasilkan pengaruhnya signifikan terhadap filial piety dan sebaliknya.

Penjelasan dari nilai koefisien regresi yang diperoleh pada masingmasing independent variable adalah sebagai berikut:. 1. Dimensi religious value dari Variabel religious commitment menunjukkan bahwa nilai koefisien regresi sebesar 0,315 dengan signifikansi $0,001(\mathrm{P}<0,05)$. Secara uji statistik berarti dimensi religious value secara positif memiliki pengaruh yang signifikan terhadap filial piety. Jadi semakin tinggi religious value remaja maka semakin tinggi pula filial piety remaja kepada orang tua. 2. Dimensi religious belief dengan nilai koefisien regresi sebesar ,049 dengan signifikansi 0, $000(\mathrm{P}<$ $0,05)$. Secara uji statistik berarti dimensi religious belief secara positif memiliki pengaruh yang signifikan terhadap filial piety. Jadi semakin tinggi religious belief remaja maka semakin tinggi pula filial piety remaja kepada orang tua. 3 . Dimensi religious practice dengan nilai koefisien regresi sebesar - 0,001 dengan signifikansi 0,039 $(\mathrm{P}<0,05)$. Secara uji statistik berarti dimensi religious practice secara negatif memiliki pengaruh yang signifikan terhadap filial piety. Jadi semakin rendah religious practice remaja maka semakin tinggi pula filial piety remaja kepada orang tua.

Variabel gratitude yang memiliki 3 dimensi menujukkan 2 dimensi tidak berpengaruh. Yaitu dimensi sense of abundance dan simple appreciation keduanya memiliki nilai koefisien di atas 0,05 . Hal ini berarti bahwa kedua dimensi tidak memiliki pengaruh yang signfikan terhadap perubahan filial piety. Sebaliknya dimensi appreciation for other memiliki nilai koefisien 
regresi sebesar 0,482 $(<0,05)$. Hal ini menunjukkan bahwa secara uji statistik memiliki pengaruh yang signifikan. Nilai koefisien bertanda positif, artinya semakin tinggi appreciation for other remaja maka semakin tinggi pula filial piety kepada orang tua.

Variabel demografi, yang terdiri dari jenis kelamin dan usia, kedua dimensi menunjukkan pengaruh yang signifikan. Jenis kelamin perempuan memiliki tingkat filial piety yang tinggi dibandingkan dnegan jenis kelamin laki-laki. Pada variable usia diperoleh nilai koefisien regresi sebesar 0,579 dengan signifikansi $0,014(\mathrm{P}<0,05)$. Secara uji statistik berarti dimensi usia secara positif memiliki pengaruh yang signifikan terhadap filial piety. Jadi semakin tinggi usia remaja maka semakin tinggi filial piety remaja kepada orang tua.

Hasil uji hipotesis penelitian ini menunjukan adanya pengaruh yang signifikan dari seluruh independent variable (religious value, religious belief, religious practice, sense of abundance, appreciation for other, simple appreciation, jenis kelamin, dan usia) terhadap dependent variable (filial piety) pada remaja di Kelurahan Ciputat, Kota Tangerang Selatan, dengan sumbangan R square sebesar 39,2\%. Artinya hipotesis mayor dalam penelitian ini diterima.

Jika dilihat berdasarkan koefisien regresi pada setiap variabel yang dihasilkan berdasarkan analisis statistik, maka variabel religious value, religious belief, religious practice, appreciation for other, jenis kelamin, dan usia memiliki pengaruh yang signifikan terhadap filial piety.

Selanjutnya berdasarkan uji dari hipotesis minor, dengan melihat dari proporsi varians independent variable (IV) terhadap dependent variable (DV) yang dihasilkan melalui analisis statistik maka variabel religious value, religious belief, appreciation for other, jenis kelamin, dan usia berpengaruh secara signifikan terhadap filial piety. Maka untuk uji hipotesis minor ada tiga hipotesis minor yang ditolak, yaitu, $\mathrm{H}_{3}$ (ada pengaruh dimensi religious practices yang signifikan terhadap filial piety remaja di Kelurahan Ciputat), $\mathrm{H}_{4}$ (ada pengaruh dimensi sense of abundance yang signifikan terhadap filial piety remaja di Kelurahan Ciputat), dan $\mathrm{H}_{6}$ (ada pengaruh dimensi simple apreciations yang signifikan terhadap filial piety remaja di Kelurahan Ciputat). Karena ketiga variabel tersebut, terbukti tidak signifikan berdasarkan hasil analisis statistik. 


\section{DISKUSI}

Penelitian ini fokus terhadap pertanyaan mengenai pengaruh religious commitment, gratitude dan variabel demografi (jenis kelamin dan usia) terhadap filial piety. Hasil dari penelitian ini menunjukan bahwa terdapat pengaruh yang signifikan dari dimensi religious value, religious belief, sense of abundance, appreciation for other, jenis kelamin, dan usia terhadap filial piety remaja di Kelurahan Ciputat, Kota Tangerang Selatan.

Temuan ini mendukung pernyataan Kunio (2004) yaitu berbakti (filial piety) merupakan syarat mutlak dalam proses pembangunan spiritual. Hal ini juga sejalan dengan yang diajarkan dalam banyak agama, salah satunya agama Islam. Sehingga semakin tinggi religious commitment semakin tinggi pula filial piety. Hanya saja dalam penelitian ini ditemukan, bahwa hanya dimensi yang merupakan religiusitas instrinsik saja yang berpengaruh terhadap filial piety, yaitu dimensi religious value, dan religious belief. Sementara dimensi religious practice yang merupakan religiusitas ekstrinsik tidak berpengaruh terhadap filial piety.

Sejalan dengan penjelasan Glock (dalam Kidwell, 2009) mengenai konsep yang disebut religious commitment, yaitu rasa keterikatan terhadap agama yang mencakup dimensi keyakinan, dimensi ritual, dimensi perasaan atau penghayatan, dimensi pengetahuan, dan dimensi konsekuensi atau pengaruh terhadap prilaku sehari-hari. Dalam agama atau budaya tertentu filial piety dapat merupakan dimensi keyakinan, dimana konsep berbakti ditanamkan sebagai doktrin melalui kisah-kisah atau pengajaran-pengajaran moral. Dalam ajaran agama sendiri, dimensi ini merupakan dimensi yang paling mendasar untuk terbentuknya internalisasi teologis dalam kehidupan seseorang (Reese, 2003). Selain itu berbakti juga dapat diartikan sebagai perasaan (Chow, 2001). Dalam komitmen religius, perasaan itu dibangun dalam kondisi mental dan emosional seseorang, di mana dalam beberapa agama, filial piety adalah salah satu konsep penting. Maka signifikannya pengaruh religious value dan religious belief sebagai religiusitas intrinsik merupakan hal yang dapat dipahami. Akan tetapi pada kalangan remaja di Kelurahan Ciputat nampaknya dimensi praktis dan konsekuensi masih dalam bentuk pengetahuan saja, belum menjadi penghayatan, karena religiusitas ekstrinsik atau religious practice tidak mempengaruhi filial piety mereka. Padahal dalam ajaran Islam sangat jelas dikatakan bahwa tidak berbakti adalah dosa yang sangat besar. 
Hal ini memungkin karena perkembangan moral dan kognitif responden yang berbeda-beda sesuai dengan kelompok usia. Berdasarkan perkembangan kognitif Piaget (dalam Papalia, Olds, \& Feldman, 2009) remaja dengan rentang usia 11 tahun - dewasa awal berada pada tahap perkembangan kognitif oprasional formal. Yaitu perkembangan kognitif pada tingkat paling tinggi ketika remaja mengembangkan cara berfikir abstrak, lebih fleksibel, pikiran bersifat umum dan menyeluruh, proporsional, dapat membuat hipotesis, egosentris, dan mengembangkan idealisme yang kuat. Selain perkembangan kognitif, perkembangan moral pada remaja pun menjadi salah satu penyebab. Kolhberg (dalam Papalia, Olds, \& Feldman, 2009) mengatakan bahwa remaja berada pada fase morality of conventional conformity, yaitu remaja seringkali mengambil standar moral orang tuanya, hal tersebut dilakukan agar dianggap sebagai -anak baik $\|$. Moral didasari atas kesetiaan dan kasih sayang. Kemudian juga berkembang moralitas sistem sosial, moral didasarkan pada pemahaman terhadap aturan atau norma, hukum, dan etika sosial. Sehingga religious commitment yang terbentuk dalam diri remaja, khususnya dimensi religious practice masih merupakan komitmen yang semu. Karena remaja melakukan religious practice masih didasarkan oleh keinginan untuk dianggap sebagai -anak baik\| dan sesuai dengan standar moral, bukan bentuk komitmen yang telah tercipta dalam dirinya.

Temuan ini juga mendukung asumsi Yeh (dalam Yeh \& Bedford, 2003) yang menyatakan bahwa filial piety adalah ekspresi dari gratitude, sehingga semakin tinggi gratitude seseorang maka filial piety akan semakin tinggi. Selain itu model dual filial piety Yeh dan Bedford (2003) yang menyatakan bahwa konsep filial piety yang selaras dengan kebutuhan modern, dapat dipahami dengan cara timbal balik, mempertahankan hubungan interpersonal yang harmonis dengan hubungan yang dekat dari kasih sayang dan rasa syukur (gratitude). Dan memiliki implikasi positif dengan tingkat hubungan yang lebih baik, sehingga konflik anak dengan orang tua semakin menurun. Berbeda dengan pandangan filial piety sebagai kewajiban (otoriter), bukan sebagai bentuk cinta kasih dan rasa syukur (gratitude), sehingga konflik anak-orang tua semakin tinggi.

Dalam penelitian ini, dari tiga dimensi gratitude hanya dimensi appreciation for other saja yang mempengaruhi filial piety. Hal ini sejalan dengan pengertian gratitude yang dikemukakan oleh Fitzgerald (1998), yaitu rasa apresiasi yang hangat untuk seseorang atau sesuatu, yang meliputi perasaan kasih sayang, dan cinta; niat baik (goodwill) yang ditujukan kepada 
seseorang atau sesuatu, meliputi keinginan untuk membantu orang yang kesusahan, keinginan untuk berbagi dan lainnya; dan kecenderungan untuk bertindak positif berdasarkan rasa apresiasi dan kehendak baik, meliputi intensi menolong orang lain, membalas kebaikan orang lain, beribadah dan hal lainnya. Begitu pula dengan pengertian appreciation for other, yang artinya adalah bersyukur dengan menghargai kontribusi jasa orang lain dalam kesejahteraan hidupnya. Hal tersebut sejalan dengan pengertian filial piety, yaitu mengandung ide-ide penting tentang bagaimana anak-anak harus merawat orang tua mereka sebagai penghargaan terhadap jasa orang lain, yang dalam konteks ini adalah orang tua. Bakti (filial piety) menuntut sesuatu yang bersifat materi dan emosional, seperti support (dukungan), memorializing (mengabadikan peringatan), attendance (kehadiran), deference (keseganan), compliance (kepatuhan), respect (rasa hormat), dan love (kasih sayang/cinta), dan konsep tersebut pada umumnya terdapat dalam budaya dan agama timur.

Temuan selanjutnya ditinjau dari variabel jenis kelamin yang memiliki pengaruh yang signifikan terhadap filial piety, meskipun ada penelitian yang menyatakan bahwa tidak ada pengaruh yang signifikan antara jenis kelamin terhadap filial piety dalam bentuk dukungan meteri, yang disebabkan oleh tingkat pendidikan dan pendapatan karena pada zaman ini banyak wanita yang bekerja dan memiliki penghasilan sendiri, sehingga merubah demografi, ekonomi, dan budaya di Cina modern (Xie dan Zhu, 2009). Menurut peneliti adanya perbedaan temuan ini dikarenakan usia subjek dalam penelitian yang berbeda, dimana dalam penelitian ini subjek adalah remaja yang sepenuhnya secara materi masih bergantung kepada orang tua. Selain itu, Salaff (1976), mengemukakan bahwa anak perempuan yang belum menikah melakukan banyak tugas berbakti. Hal ini sejalan dengan hasil penelitian dimana hasil penelitian menunjukan bahwa responden remaja perempuan memiliki filial piety yang lebih tinggi dibandingkan dengan responden remaja laki-laki.

Tetapi dalam penelitian lain, dimana responden penelitian bukan remaja, seperti penelitian Yue dan Ng (1999) yang mencatat perbedaan gender dalam praktek filial piety di kalangan anak muda di Beijing. Yaitu tuntutan untuk anak laki-laki adalah membantu orang tua yang lanjut usia secara finansial, sedangkan wanita lebih peduli tentang menjaga hubungan dengan orang tua. Yi dan Lin (2009) menemukan pola yang sama di Taiwan, di mana anak-anak perempuan yang sudah menikah yang ingin menjaga kontak sesering mungkin, memberikan dukungan emosional, dan 
terlibat dalam pertukaran fungsional seperti bantuan timbal balik dalam pekerjaan rumah tangga. Studi yang dilakukan di Hong Kong oleh Chan dan Lee (1995) dan Ngan dan Wong (1995) mengungkapkan bahwa anak laki-laki membuat sebagian besar keputusan keluarga dan memberikan dukungan keuangan kepada orang tua, sedangkan anak perempuan mengambil bagian lebih besar dari tugas peduli secara emosional.

Hasil penelitian selanjutnya adalah adanya pengaruh yang signifikan dari variabel usia terhadap filial piety. Selain itu penelitian juga memperlihatkan bahwa semakin tinggi usia, maka semakin tinggi pula filial piety seseorang. Hal tersebut sejalan dengan pemaparan Steinberg (Santrock, 2002; h. 42), yang menyatakan adanya perkembangan perubahan biologis pubertas, perubahan kognitif yang meliputi peningkatan idealisme dan penalaran logis, perubahan sosial yang berfokus pada kemandirian dan identitas, kearah yang lebih matang, sesuai dengan perkembangan remaja tersebut. Hal tersebut sejalan dengan pertambahan usia remaja. Hal tersebut diperkuat oleh pernyataan bahwa konflik dengan orang tua sering kali meningkat selama masa awal remaja, kemudian stabil, dan berkurang pada usia 17 hingga 20 tahun (Sullivan \& Sullivan, dalam Santrock, 2002). Selain hal tersebut, dalam penelitian ini, peneliti mendapati bahwa responden pada usia 17-20 tahun ( remaja akhir) sudah mulai terlepas dari orang tua, karena pada umumnya mereka mulai bekerja, atau kuliah, sehingga intensitas interaksi dengan orang tua berkurang, hal ini menyebabkan ketegangan antar generasi berkurang. Hal tersebut juga didukung oleh penelitian dari Goh dan Göransson (2011).

Berdasarkan hasil penelitian dan diskusi yang telah diuraikan di atas, yang dapat dijadikan pertimbangan bagi penelitian selanjutnya yang terkait penelitian serupa.

Variabel religious commitment (religious value, religious belief, religious practice), gratitude (sense of abundance, appreciation for other, simple appreciation), usia, dan jenis kelamin secara bersama-sama telah memberikan sumbangan terhadap 39,2\% terhadap filial piety remaja. Saran untuk penelitian selanjutnya perlu lebih memperhatikan indikator-indikator yang ada pada masing-masing variabel, sehingga tidak hanya secara keseluruhan tapi masingmasing dimensi atau determinan variabel akan memberikan sumbangan yang besar pula.

Selanjutnya, untuk menanamkan religious value dan religious belief pada remaja, dapat dilakukan dengan cara pembinaan mental dan spiritual, dengan menyebar luaskan ajaran agama dan moral, melalui kelompok- 
kelompok dan organisasi-organisasi keagamaan seperti kelompok remaja masjid. Program-program keagamaan yang dapat dilakukan dalam kelompok keagamaan dapat berupa pengajian, penyuluhan, gathering, dan lainnya. Sehingga penanaman filial piety pada remaja dapat disampaikan dan dikaji dalam kegiatan kelompok/organisasi keagamaan.

Untuk menanamkan appreciation for other pada remaja, dapat dilakukan dengan mengisi program-program karang taruna dengan kegiatan yang bermutu. Seperti kegiatan-kegiatan sosial, kompetisi olah raga antar RW/RT, dan kegiatan yang dapat menyalurkan kreatifitas dan hobi. Sehingga remaja dapat menyalurkan sportifitas dan kepekaan sosialnya, dan diharapkan dapat meningkatkan apresiasi atau penghargaan remaja kepada orang lain.

\section{DAFTAR PUSTAKA}

Bahrudin A. G. (2008). Panti jompo jadi alternatif?. Diunduh tanggal 15 Februari 2015 dari www.pikiran-rakyat.com

Biaz, D. (2014). Ditelantarkan selama 23 tahun, anak laporkan ayahnya ke polisi. Diunduh tanggal 10 Februari 2015 dari www.detik.com

Cardwell, J. D. (1969). The relationship between religious commitment and premarital sexual permissiveness: A five dimensional analysis. Sociological analysis, Oxford University Press, 30(2), 72-80.

Chen, S. T., Chan, W., \& Chan, A. C. M. (2008). Older people's realization of generativity in changing society: the case of Hong Kong. Ageing and society 28(5), 609-627.

Cheung, C., \& Kwan, A. Y. H. (2009). The erosion of filial piety by modernization in Chines cities. Ageing and society, 29(2), 179-198.

Chow, N. (2001). The practice of filial piety among the Chinese in Hong Kong. Elderly Chinese in pacific rim countries: social support and integration, 23(1), 125-136.

Davidson, J. D., \&Knudsen, D. D. (1977). A new approach to religious commitment, Sociological focus, Perdue University, 10(2), 151-173.

Dessi, U. (2010). Social behavior and religious consciousness among Shin Buddhist practitioners. Japanese journal of religious studies, (37)2, 335366.

Emmons, R. A., \& Kneezel, T. T. (2005). Giving thanks spiritual and religious correlates of gratitude. Journal of psychology and Christianity, 24(2), $140-148$.

Endang. (2014). Diduga melakukan wanprestasi, orangtua dilaporkan ke polisi. Diunduh tanggal 10 Februari 2015 dari www.liputanenam.com 